\title{
Structural Performance of Steel Fibre Reinforced Lightweight Concrete Frames Subjected to Lateral Load
}

\author{
Muthukannan M, Vinod Kumar M
}

\begin{abstract}
Masonry infilled Reinforced Concrete (RC) framed structure is the utmost common kind of building in which, $R C$ frames contribute in resisting lateral forces. Due to heavy mass and rigid construction, the $R C$ framed buildings performs unfortunate under lateral forces. Practice of Lightweight concrete $(L W C)$ is superlative because the dead load of concrete is massive. Low density materials are chosen in $L W C$, reduces the mass of the building thus decreasing the influence of lateral forces. However, LWC having a lesser modulus of elasticity has a more rapidly develops the cracks in the $R C$ members. In this investigation, pumice is a naturally available material of volcanic source, has low density, which creates it ideal for production of $L W C$, likewise steel fibres are employed as an additive to enhance the energy absorption ability and to reduce the possibility of development of the cracks. In the present paper the structural behaviour of Lightweight $R C$ framed structures realized by using steel fibres and subjected to lateral forces, In this study, four RC frames viz., F1-NWC (Control), F2- NWCF (with 1\% Vf of steel fibres), F3-LWC (with 20\% substitute of coarse aggregate instead of pumice aggregate) and F4-LWCF (with $20 \%$ substitute of coarse aggregate instead of pumice aggregate and $1 \% \mathrm{Vf}$ of steel fibres) were casted and tested under in-plane horizontal loading, which are designed according to Indian Standard (IS) code IS 456 (2000). It was observed that the behaviour of F4-LWCF significantly better in comparison to other frames in various parameters such as load carrying capacity, displacement, ductility, stiffness and energy dissipation.
\end{abstract}

Keywords: Lateral forces, Lightweight concrete (LWC), Pumice aggregate, Steel fibres.

\section{INTRODUCTION}

A typical Reinforced Concrete (RC) building is made of horizontal elements (namely slabs and beams) and vertical elements (namely walls and columns) and those elements are supported by the sub structure (namely foundations) which is rest on the soil surface. The structure consists of RC frame. The RC frame contributes to contradict the lateral forces. Concrete having higher density enhances the building's dead loads. Thus, it enriches the foundational loads and earthquake forces approaching to the structure. In order to eradicate this shortcoming of the concrete, the density desires to be reduced.

Revised Manuscript Received on December 30, 2019.

* Correspondence Author

Muthukannan $\mathbf{M}^{*}$, Department of Civil Engineering, Kalasalingam Academy of Research and Education, Tamil Nadu, India. Email: civilkannan@gmail.com

Vinod Kumar M, Department of Civil Engineering, Vel Tech Rangarajan Dr. Sagunthala R\&D Institute of Science and Technology, Chennai, India. Email: m.vinodkumar.civil@gmail.com
Unique concrete created for this purpose is the Lightweight concrete (LWC). The dead load and earthquake forces decreases, when it is used in a building due to implementation of LWC. This reduces the dimensions of the building structural elements, as a result the load approaching to the foundational becomes less and thus leads to decreases the overall cost of the structure. LWC hastens the enlargement of cracks due to lower elasticity module. Thus, it may have an opposing result. However, for improvement of the concrete characteristics, fibres are used. The substantial part of fibres is resisting the development and formation of cracks. Apart from that, it improves the flexural and fatigue strength of RC. In recent years, steel fibres are incorporated into concrete in RC frames, highways, tunnel linings, concrete pipes, shell roof systems, light shell constructions, skyscrapers and domes. Furthermore, LWC manufactured using steel fibres enhances the resistance of the concrete in contradiction of deformation, tensile strength of the concrete, load carrying capacity and toughness of the concrete members. Thus, cracks are controlled to greater extent and it shows an excessive resistance to unexpected and dynamic loadings though reducing the width of the crack. As a result, economical resolutions are achieved by reducing the dead load of the structure.

\section{LITERATURE REVIEW}

A case study was prepared by Semsi Yazici et al., (2007) on the consequence of aspect ratio and volume fraction of steel fibres added on the concrete to examine mechanical properties of Steel Fibre Reinforced Concrete (SFRC). Hook ended steel fibres of different aspect ratio (45, 65 and 80) and volume fraction $(0.5 \%, 1.0 \%$ and $1.5 \%)$ was added to concrete. From the experimental results, it was found that, the compressive, split tensile and flexural strength of SFRC affects noticeably accordance with steel fibre's aspect ratio and volume fraction. SFRC has enhanced compressive strength with $1 \%$ of steel fibres and aspect ratio of 80 . Likewise, there is an improvement in flexural strength of SFRC with increase in aspect ratio of fibres.

Hasan Oktay et al., (2015) did an experimental investigation for producing relatively high strength and low density concrete. Various types of lightweight aggregates were utilized in this investigation namely pumice (PA), expanded perlite (EPA) and rubber aggregates (RA) with replacement ranging from $10 \%$ to $50 \%$ in $10 \%$ increments. The test result reveals that the incorporation of $\mathrm{PA}, \mathrm{EPA}$ and RA reduces the bulk density of material and thus decreases the compressive strength 
of LWC. It was found that the concrete made with $20 \%$ of pumice aggregates had better mechanical properties. The dropdown in load carrying capacity of RC frame under lateral forces can be made gradual by improving its ductility. During the investigation, it was identified that, the SFRC changes the failure pattern from brittle failure to ductile failure, thus incorporation of steel fibres incapacitating the challenge of concrete brittleness. The ductility is enhanced with increasing the aspect ratio and volume fraction of steel fibres in concrete. The strength of SFRC is promising up to $1 \%$ of volume fraction. Density of concrete reduced with increase in partial replacement percentage of pumice aggregate up to $20 \%$ instead of course aggregate, better strength is achieved.

Lila Abdel-Hafez et al., (2015) did a test in laboratory on single storey frames due to application of lateral force. Three different types of RC frames were casted and tested under lateral force such as control $\mathrm{RC}$ frame, $\mathrm{RC}$ frame infilled with masonry and RC frame strengthened with Glass fibre reinforced polymer sheets and ferrocement meshes. The RC frames were tested through cyclic loading using servo-controlled hydraulic actuator and the response were documented using a computing facility (namely, data acquisition system). Lateral displacements were recorded at various places in the columns and base beam using LVDT's. It is concluded that the non-ductile frame showed sophisticated quantity of pinching related to the ductile frame, and thus reduced amount of energy and the decrease in load carrying capacity for ductile frames. The crack pattern witnessed in both frames was alike, but in non-ductile frames, the cracks were initiated earlier and the amount of cracks developed was higher than the ductile frames.

\section{MATERIAL USED}

Ordinary Portland Cement (OPC) of 53 grade with specific gravity 3.15 was used for preparation of test specimens, which satisfies the requirement of IS 12269 (1987) specifications. Locally existing river sand was used as fine aggregate which passed through $2.36 \mathrm{~mm}$ size sieve having specific gravity 2.65 and fineness modulus 2.75 conforming to grading zone III of IS 383 (1970) specifications. Crushed angular granite stone with $12 \mathrm{~mm}$ maximum size was used as coarse aggregate conforming to IS 383 (1970) specifications and having specific gravity 2.72 and fineness modulus 6.64. Similarly, the pumice was used as a partial replacement of coarse aggregate and having specific gravity 1.85 and fineness modulus 7.17. The potable water was used for mixing and curing the concrete. Super-plasticizer were added in the dosage range of $500-1,500 \mathrm{ml}$ per $100 \mathrm{~kg}$ of cement to achieve good workability and durability with specific gravity of 1.08 as per IS 9103 (1999) and ASTM C494-type F. In this investigation, steel fibres was used to enhance the strength of the specimen and also to arrest the propagation of cracks. The properties of steel fibres are provided in Table 1.

Table- I: PROPERTIES OF STEEL FIBRE

\begin{tabular}{|l|l|}
\hline Parameters & Values \\
\hline Length $(\mathrm{mm})$ & 60 \\
\hline Diameter $(\mathrm{mm})$ & 0.75 \\
\hline
\end{tabular}

\section{TEST SPECIMENS}

\section{A. Description of Test Specimens}

The frame was designed with a span of $1200 \mathrm{~mm}$, a storey height of $1250 \mathrm{~mm}$, and an overall height of $1500 \mathrm{~mm}$; a 200 $\mathrm{mm}$ heavily reinforced concrete base was integrated to the frame. The beam was $100 \mathrm{~mm}$ and $100 \mathrm{~mm}$; columns were $100 \mathrm{~mm}$ and $100 \mathrm{~mm}$. Concrete mix proportion was calculated as per the design guidelines of IS 10262 (2009). Concrete with the cube compressive strength of $25 \mathrm{MPa}$ was used. The reinforcement details are presented in Fig. 1. In this study, four RC frames viz., F1-NWC (Control), F2- NWCF (addition 1\% Vf of steel fibres), F3-LWC (Pumice aggregate replaced by coarse aggregate with 20\%) and F4-LWCF (Pumice aggregate replaced by coarse aggregate with $20 \%$ and addition of $1 \% \mathrm{Vf}$ of steel fibres) were casted and tested under in-plane horizontal loading, which are designed according to Indian Standard (IS) code IS 456 (2000). Steel fibres are mixed through out the concrete during casting of specimens. So, the fibres are used in the entire members of the specimens. Coarse aggregate higher replacement of pumice stone in concrete also leads to the formation of voids and increases water demand in concrete [Kalpana et al., (2015)]. So, in this investigation, pumice aggregate replaced by coarse aggregate with $20 \%$ not to increase the water demand of the concrete mixes.

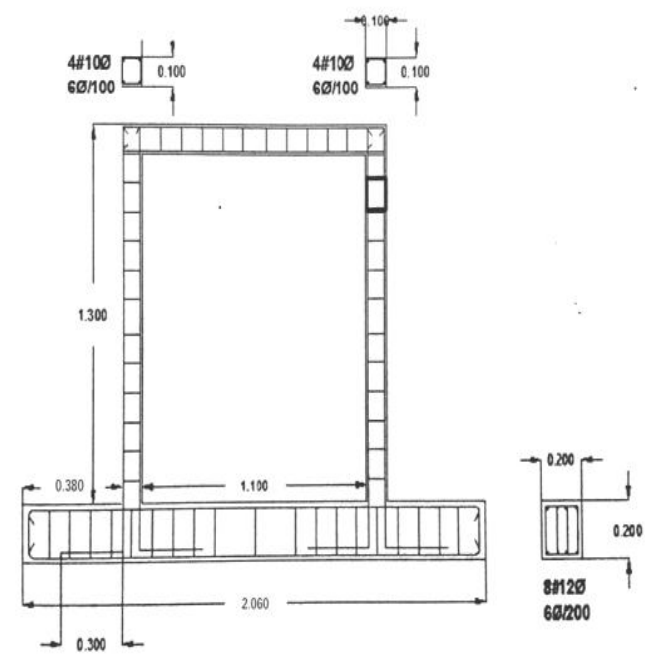

Specimen dimensions are in meter and Reinforcement dimensions are in millimeter

Fig. 1. Dimensions and Reinforcement Details of Specimens

\section{B. Test Setup and Instrumentation}

Fig. 2 shows the over-all test setup for RC frames. The RC frames were tested under lateral loading. Lateral load was applied to the RC frames through a hydraulic actuator. The specimens were placed and their foundation beam was clamped to the solid floor by bolts to prevent displacement and rotation. Lateral displacement was noted using Linear Variable Differential Transducer (LVDT). LVDT was placed on the independent scaffolding so that absolute displacements can be measured. During the whole test process, the force and displacement were recorded electronically. 


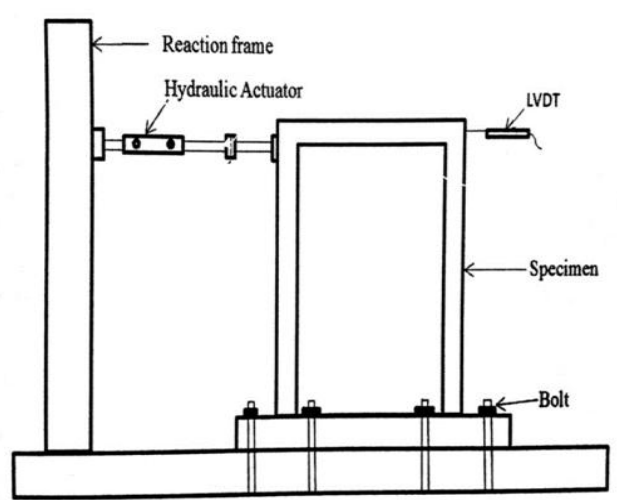

Fig. 2. General arrangement of the test setup

\section{RESULT AND DISCUSSION}

The experimental results are summarized below.

\section{A. Modes of Failure}

Crack pattern (failure mode) may facilitate to understand the resistance mechanism in the specimens. The crack patterns of each specimen resulting from the application of lateral load to the frames are shown in Fig. 3. The bottom of the beam-column connections was observed by the presence of hair cracks. These cracks seemed at cycle 3 for the RC frames F1, F3 and F4. In beam-column connections, diagonal cracks appeared and propagated at higher load carrying capacity with repetitive cycles. Flexural and horizontal cracks were originated and detected at the ends of the beam and underside of the columns respectively.
F1 (NWC)

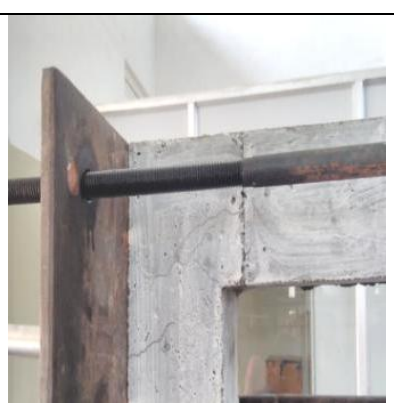

F3 (LWC)

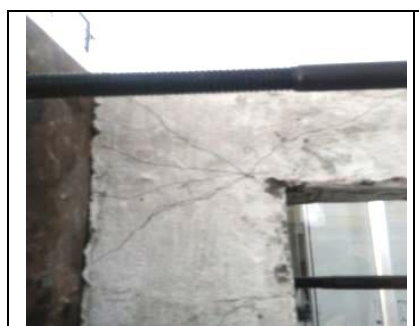

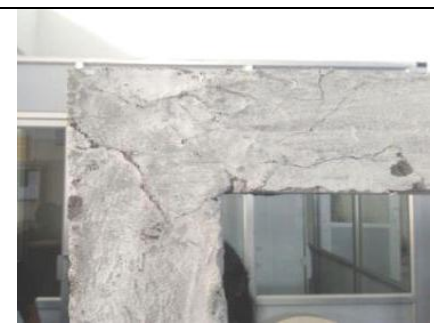

F2 (NWCF)

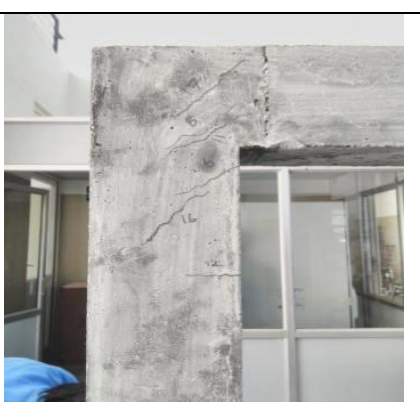

F4 (LWCF)
Fig. 3. Observation of Cracks (Far end of loading during) Test

\section{B. Lateral Load-Displacement Relationships}

Strategies of hysteresis loops for the realistic horizontal load of the RC frames and the envelopes are shown in Fig. 4 for F1
(NWC), F2 (NWCF), F3 (LWC) and F4 (LWCF). The hysteresis loops were fairly symmetrical in the forward and reverse directions of loading. Table 2 shows the ultimate load and displacement values for all tested RC frames. The examination of the presented in form of figures and tables specifies the performance of the specimes, taking place elastic up to a definite point afterward which the behavior transformed to plastic. Likewise, it can be observed that:

In case of F2 (NWCF), the horizontal load enhanced by $4 \%$ compared to frame F1 (NWC).

In case of F3 (LWC) in comparison to frame F1 (NWC), the lateral load enhanced by $7 \%$.

In case of F4 (LWCF) in comparison to frame F1 (NWC), the maximum lateral load enhanced by $8 \%$.

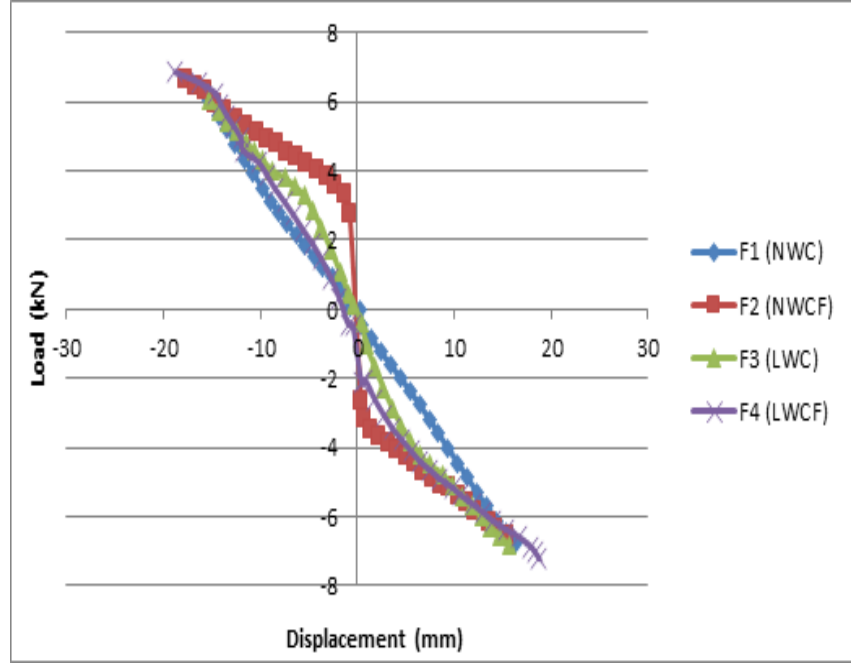

Fig. 4. Envelope of the hysteresis loops of all specimens

\section{Table- II: ULTIMATE LATERAL LOAD AND RELATIVE DISPLACEMENT FOR ALL SPECIMENS}

\begin{tabular}{|l|c|c|}
\hline Specimens & $\begin{array}{l}\text { Ultimate } \\
\text { lateral load } \\
(\mathbf{k N})\end{array}$ & $\begin{array}{l}\text { Relative } \\
\text { displacement } \\
(\mathbf{m m})\end{array}$ \\
\hline F1 - NWC & 6.362 & 16.350 \\
F2 - NWCF & 6.600 & 17.712 \\
F3 - LWC & 6.832 & 15.703 \\
F4 - LWCF & 6.859 & 18.763 \\
\hline
\end{tabular}

\section{Stiffness}

Stiffness means the range of realistic load $(\mathrm{Pi})$ to the deformation $(\Delta \mathrm{i})$. The stiffness value of all $\mathrm{RC}$ frames was intended for all loading cycle is expressed by Equation. (1): $\mathrm{K} \mathrm{i}=\mathrm{Pi} / \Delta \mathrm{i}$

Fig. 5 shows the Stiffness degradation because of cycling. The initial stiffness is distinct by the slope of the load Vs displacement curve for the first 5 cycles. From this Fig. 5, it can be observed that, there is no change in the initial stiffness even though steel fibres were incorporated in the concrete. Though, degradation of stiffness decreases with increase in number of cycles. The overhead conduct may be endorsed to the datum that at first few cycles, micro-cracks are not originated and henceforth the steel fibres were not operative in the nonappearance of cracks. Later on increasing the number of cycles results in the development of micro-cracks, which are spread at unsystematic. Thus, inclusion of steel fibres has a tendency to control the propagation of cracks. 


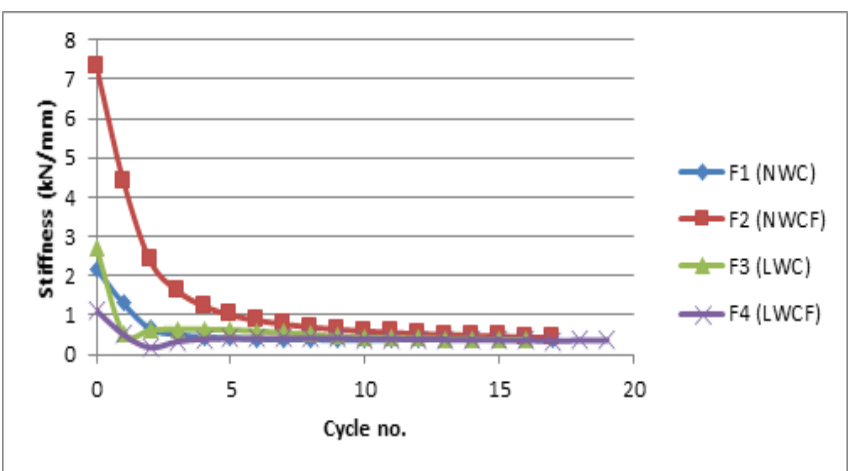

Fig. 5. Stiffness degradation due to cycling

\section{CONCLUSION}

- In this experimental investigation, the structural performance of four frames F1 (NWC), F2 (NWCF), F3 (LWC) and F4 (LWCF) under cyclic in-plane lateral load was investigated. The tests resulted in important information about the failure patterns strength and stiffness of the frames tested under similar restraint conditions. The following are the conclusion based on the experimental test results:

- The frames with steel fibres (both normal and lightweight concrete) viz., F2 (NWCF) and F4 (LWCF) resisted the same loading cycles with increasing displacement, without any loss in strength. Frame F4 (LWCF) recorded highest displacement of all other frames.

- Load carrying capacity of frames increased with addition of steel fibres. In case of F2 (NWCF), the horizontal load enhanced by $4 \%$ compared to frame F1 (NWC). In case of F3 (LWC) in comparison to frame F1 (NWC), the lateral load enhanced by $7 \%$. In case of F4 (LWCF) in comparison to frame F1 (NWC), the maximum lateral load enhanced by $8 \%$.

- $\quad$ Frame F3 (LWC) was found to have higher stiffness, which resisted a maximum lateral load of about $7 \%$ than Frame F1 (NWC).

- Addition of steel fibres decreased the stiffness noticeably as compared to the frame without addition of fibres.

During testing, it has been prominent that inclusion of steel fibres could enhance the dimensional steadiness and reliability of the joints. Number of cracks formed in theF2 and F4 was less when compared to F1 and F3 because of incorporation of fibres in the specimens. Moreover, in the beam-column joints, it is promising to decrease the congestion of steel reinforcement by inclusion of steel fibres.

\section{REFERENCES}

1. ASTM C494 Type F "Standard specification for chemical admixtures for concrete".

2. Hasan Oktay, RecepYumrutas and Abdullah Akpolat (2015), 'Mechanical and thermophysical properties of lightweight aggregate concretes', Construction and Building Materials, Vol. 96, pp. 217-225.

3. R. Kalpana R, Kothai (2015), "Study on Properties of Fibre Reinforced Light Weight Aggregate Concrete", International Journal for Scientific Research \& Development, Vol. 3, pp. 1876-1879.

4. IS: 12269 (1987), "Indian standards-specification for 53 grade ordinary Portland cement".

5. IS: 383 (1970), "Indian standards-specification for coarse and fine aggregates from natural sources for concrete".
6. IS: 9103 (1999), "Indian standards-specification for concrete admixtures".

7. IS: 10262 (2009), "Guidelines for Concrete Mix Proportioning".

8. IS 456 (2000), "Code of Practice for Plain and Reinforced Concrete".

9. Lila Abdel-Hafez, Abouelezz and FasealElzefeary (2015), 'Behaviour of masonry strengthened infilled reinforced concrete frames under in-plane load, Housing and Building National Reasearch Journal, Vol. 11, pp. 213-223.

10. [10] SemsiYazici, GozdeInan and VolkanTabak (2007), 'Effect of aspect ratio and volume fraction of steel fibre on the mechanical properties of SFRC', Construction and Building Materials, Vol. 21, pp. 1250-1253.

\section{AUTHORS PROFILE}

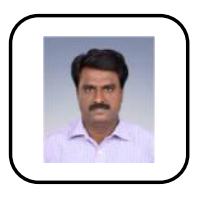

Dr.Muthukannan $\mathbf{M}$ completed his Ph.D in Civil Engineering in Anna University, Chennai in the year 2010. He completed Master of Engineering in the field of Transportation Engineering and Management in College of Engineering, Guindy, Chennai in the year 2004. He completed his Bachelor of Engineering under Madurai Kamarajar University in the year 2000. He is presently working as a Professor in Civil Engineering department at Kalasalingam University, Tamilnadu, India. He is guiding for many Ph.D scholars in the field of transporation engineering and computer applications in transportation network using graph theory. He has published various quality papers in the reputed journals. His main thrust research areas are transportation network design, transport management and travel demand management.

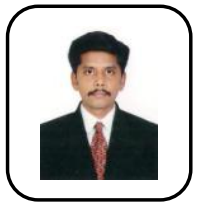

Dr. M. Vinod Kumar obtained his Bachelor's degree in Civil Engineering from Anna University, Chennai, India. Then he obtained his Master's degree in M.E Structural Engineering from Annamalai University, Chidambaram, India and another Master's degree in M.B.A Project Management from Alagappa University, Karaikudi, India. He was awarded Doctorate Degree in Structural Engineering from Kalasalingam University, Krishnankoil, Tamil Nadu, India. Currently, working as an Associate Professor at the Department of Civil Engineering, Vel Tech Rangarajan Dr. Sagunthala R\&D Institute of Science and Technology, Chennai, Tamil Nadu, India. As a Renowned resource person, he extends his research knowledge by guiding the $\mathrm{Ph} . \mathrm{D}$ projects in significant area and having totally 41 research publications. He is having membership in many professional bodies. His specializations include Theory of Structures, Design of RC and Steel Structures and Prefabricated Structures. His current field of research includes Hybrid Fibre Reinforced Concrete, Retrofitting of RC beams, Columns, Infilled frames and Beam column Joints.Second Author profile which contains their education details, their publications, research work, membership, achievements, with photo that will be maximum 200-400 words. 